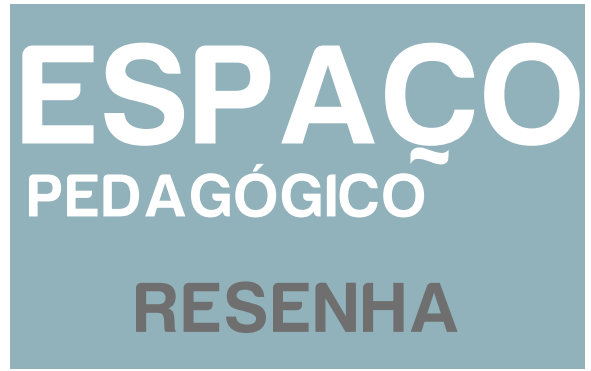




\section{Paulo Freire mais do que nunca: uma biografia filosófica}

Márcio Luís Marangon*
Volnei Fortuna*

A presente resenha trata de uma apresentação do livro Paulo Freire mais do que nunca: uma biografia filosófica, publicado no ano de 2019, pela Editora Vestígio, do Grupo Autêntica, de Belo Horizonte. Nele, o autor Walter Kohan dialoga sobre o que seria uma educação com características freireanas, compreendendo inclusive o horizonte político da tarefa de educar, mas, principalmente, compreendendo a educação baseada em cinco princípios basilares da vida e da educação pensada por Freire - a vida, a igualdade, o amor, a errância e a infância.

O primeiro princípio é a vida. Com esse princípio, Kohan demonstra como Freire dialoga sobre a conexão entre a dimensão da educação política e a dimensão da educação filosófica, ambas articuladas à vida. Nesse contexto, pensa a educação como forma de vida emancipada e transformadora, tocando-a e afetando-a politicamente, o que aumenta a intensidade do ato de viver a vida e seu sentido.

Para Kohan, Freire é um autor que foi se construindo no decorrer de sua vida e que, nessa construção, foi mudando a forma de pensar - o que fica explícito na especificidade de cada tempo e obra. Essa mudança, porém, faz com que a tentativa de compreensão de sua caminhada e de suas influências filosóficas seja longa e complexa. Freire incorpora pensamentos que vão desde a corrente filosófica marxista revolucionária, passando por: teologia da libertação, existencialismo, fenomenologia, pedagogia crítica, escolanovista, personalista, até - nos últimos anos de sua vida - a racionalidade neoliberal. A partir dessas leituras e produções, deixa clara sua antipatia ao sistema neoliberal e sua simpatia pelo "pós-modernismo progressista".

Recebido em 04/05/2020 - Aprovado em 28/09/2020

http://dx.doi.org/10.5335/rep.v27i3.

Graduado em Filosofia e Pedagogia. Pós-Graduado em Gestão Educacional. Mestre e Doutor em Educação pela Universidade de Passo Fundo. Atualmente é professor e Coordenador Pedagógico na Rede Notre Dame. Orcid: http:// orcid.org/0000-0003-3020-4429. E-mail:mlmarangon@yahoo.com.br

Mestre em Educação e doutorando em Educação na Universidade de Passo Fundo. Atua no Colégio Salvatoriano Bom Conselho, Passo Fundo, como Coordenador Pedagógico Pastoral, desenvolvendo processos formativos e projetos pedagógico-pastorais com educadores e estudantes. Orcid: https://orcid.org/0000-0003-3047-2300. E-mail: fortunavolnei@gmail.com 
A partir das análises de suas obras, fica clara também a conscientização intrinsecamente associada à tradição fenomenológica, que carrega o propósito de abrir o horizonte dos sujeitos diante da opressão e de suas posições na sociedade, para que posteriormente façam um movimento de transformação. Para tanto, Freire traz a indissociabilidade filosófica entre teoria e prática, reflexão e ação, pensamento e vida, afirmando, em seu marxismo, a contemplação dos problemas da educação na transformação da prática educativa: a educação não é a alavanca da transformação da sociedade, mas tem de se ter presente que, sem ela, a transformação não acontece.

Por outro olhar, ao perceber que Foucault reflete sobre a "metafísica da alma", tendo a filosofia como forma ou sabedoria da vida e denominando-a de "estética da existência”, sabe-se que o autor destaca a filosofia como problematização da vida, como conhecimento, sistema de pensamento, atividade intelectual. Em Foucault, uma vida filosófica é uma vida educadora: o que torna herói o sujeito da filosofia é seu exemplo, que se dá pela sua vida. A vida "só pode ser vivida se inspira outras vidas".

Segundo Kohan, Freire acredita na tradição de vida educadora, política, ética e heroica, disposta por Foucault através de Sócrates e os filósofos cínicos. Por isso, parte do pressuposto do inacabamento, que abre um leque de possibilidades para despertar no sujeito a passagem do estar-sendo para o ser-mais. Assim, a filosofia de Freire consiste em fazer da vida um pensamento que luta contra as forças de dominação existentes na sociedade, de modo que a leitura de suas obras abra caminhos para a percepção da vida, bem como, para pensar a possibilidade de outra escola e de outra educação.

O segundo princípio é a igualdade. De acordo com Kohan, Freire enfatiza a igualdade como conceito que pressupõe a inexistência de superioridade e inferioridade. A educação política subentende que todas as vidas valem igualmente, tanto na individualidade quanto na coletividade. O conceito de igualdade, apresentado por Freire em Pedagogia da Autonomia: saberes necessários à prática educativa, por exemplo, afirma-se na ideia de que ninguém é superior a ninguém.

Concatenado à ideia de igualdade, a escuta, a amorosidade, o gosto pela vida, pelo novo e a humildade são virtudes que demonstram a aceitação e o respeito à diversidade. Destaca-se a humildade como virtude essencial aos sujeitos, perpassando a ética, a política e a epistemologia, sendo assim, uma virtude pedagógica. Já a igualdade, enquanto princípio ontológico, conecta-se à emancipação social dos sujeitos. É um tema político, associado à dimensão econômica, social, cultural e 
educativa. Isso porque, na relação de desigualdade, a superioridade e a inferioridade entre sujeitos quebram a possibilidade de diálogo e construção individual e coletiva.

Seguindo essa lógica, é a inexistência de superiores e de inferiores que indica a inexistência da desigualdade, ou seja, na igualdade existem somente sujeitos iguais. Para Freire, essa lógica sugere algo que pode parecer dúbio: que os sujeitos respeitem as diferenças, ao mesmo tempo em que compreendam o "outro" como igual.

Essa mesma relação social é percebida também na dimensão educativa. Havendo vida superior e inferior na relação educador-educando, aufere-se obediência e relação vertical, sem diálogo e nem escuta, constituindo uma educação tradicional. Por isso, a educação libertadora não pode ser considerada uma questão de método, mas um estabelecimento de relações epistemológicas e sociais diferentes, exigindo compromisso para a abertura de horizontes educacionais que caminhem insistentemente para a emancipação. A hierarquia decorrente da educação tradicional é incompatível com a igualdade desenvolvida pela educação problematizadora. No entanto, é determinante que o educador ensine exercendo a liberdade, para que o educando aprenda com ela. $\mathrm{O}$ educando livre não aceita educador autoritário, porque confia na própria capacidade intelectual para aprender. Entende que é igual por ser diferente, e que pode, deve respeitar e ser respeitado nessa diferença.

Em meio a todo este processo, compreende-se que a emancipação que Freire problematiza em seus escritos vai além da intelectual e cognitiva: ela precisa atender também à complexidade social, econômica e política, à qual a educação está intimamente associada. Emancipar, para o educador, significa proporcionar aos sujeitos o dito da própria palavra. O educador emancipador, libertador, democrático tem a responsabilidade de empoderar o educando à práxis, ao exercício da autonomia.

Nota-se, então, que a igualdade - em Freire - é essencial e transversal para uma política da relação pedagógica. O conhecimento entre educador e educando não pode ser compreendido como hierarquizado pela posição em que cada sujeito ocupa. Entre os sujeitos, existem valores epistemológicos diferentes, mas isso não quer dizer que um tem legitimidade e outro não. Não existe desigualdade de conhecimento, mas saberes diferentes que se complementam entre si e com o mundo. Por isso, a escola não pode ser considerada pública quando desiguala os iguais ou quando alguns estudantes podem mais que outros na relação pedagógica. 
A dialética freireana tem significância quando o ensino e a aprendizagem ocorrem na medida em que todos são ouvidos e atendidos de igual para igual. Ao ensinar, o educador aprende e, ao aprender, o educando ensina. A diferença é a que alimenta a relação pedagógica assentada na igualdade, por isso, não deve ser percebida como desigualdade. Esses aspectos tornam a relação pedagógica enriquecedora, contribuindo para transformação da vida e da sociedade.

O terceiro princípio é o amor, ou o entendimento de que educar é um ato amoroso e de que o amor é também um ato político, de viver a vida para expandi-la e nunca para reduzi-la. Para indicar o que é o amor, em Freire, o autor retoma a vida de Sócrates, um mestre do amor. Segundo Kohan, Freire recria o enigma (ou mistério) do Eros pedagógico apontado por Sócrates. Na obra Pedagogia do Oprimido, por exemplo, o amor é um pilar, uma condição da verdade, por isso, ao estabelecer essa forma de amor, demonstra que é diálogo enquanto expressão de coragem e compromisso com os outros seres; é, também, um ato de compromisso com a libertação dos oprimidos, pois buscar a libertação é entender que não é possível o amor quando há opressão e não liberdade. Assim, essa ideia do amor torna o capitalismo inaceitável, principalmente porque, para Freire, o capitalismo torna impossível amar de verdade.

A amorosidade é tão importante na pedagogia de Freire a ponto de ser mencionada como uma condição essencial - e possível - para ser educador: se não houver como amar, não há como educar, ensinar e aprender - eis o saber principal da educação. Quando se ama educar, se sabe encontrar, no tempo Chrónos, a suspensão do tempo de escola como instituição, para habitar o tempo Skholé, espaço para tempo livre. Por isso, o amor torna o tempo da escola tempo Kairós, o tempo da oportunidade, o momento preciso em que a educação pode acontecer.

Nesse contexto, a amorosidade filosófica do educador não deve ser ingênua, mas política, situada. É feita na luta, na resistência, no canto pelo direito de cantar, de amar e ser amado, de ensinar e de ser ensinado, de aprender e de ser aprendido. Exige luta, compromisso, ousadia. $\mathrm{O}$ amor precisa estar em defesa do direito de amar e ensinar, na busca por um mundo mais amoroso. Precisa estar na defesa do tempo Kairós, da Skholé.

Em sua forma de expressar seu amor pela educação freireana, Kohan pensa na luta cotidiana do educador, nas péssimas condições de trabalho e salário, no descaso do poder público para com a educação pública, na repressão constante que os educadores sofrem. Assim, sua forma de educar é amar questionando, dialogando, pensando, aprendendo. 
Diante disso, lembra Kohan, quando se fala em "expurgar a ideologia de Paulo Freire", fala-se em tentar expurgar uma ideologia do amor. Do amor à resistência daquilo que nega uma educação para todos, àquilo que mascara e afasta a consciência dos problemas da educação na atualidade. Em sua última entrevista, lembra Kohan, Freire afirma que gostaria de ser recordado como alguém que, "antes de mais nada, amou profundamente tudo o que estava a seu redor". Amou a vida como expressão primeira e última de sentido para uma presença amorosa no mundo, fazendo sempre o que queria fazer com uma única condição: que a tentativa fosse amorosa.

O quarto princípio é a errância. Na pedagogia de Freire, um educador é alguém que se desloca, fisicamente e cognitivamente, e assim o faz para mostrar que o mundo é aberto e pode sempre ser de outra maneira. Não é algo que pode ser antecipado, mas precisa ser construído.

Para Kohan, Freire é um mestre errante nos dois sentidos do verbo errar: primeiro, porque anda por mais de cem cidades dos cinco continentes, percorrendo os cantos mais inóspitos, desolados, desatendidos do mundo; segundo, no sentido de que, como ser humano, erra bastante, equivoca-se, e não tem vergonha disso, pois este é um princípio pedagógico: errar faz parte da aventura de conhecer e conhecer-se, de se rever e se aperfeiçoar. A boniteza do ato pedagógico de Freire também se dá, portanto, pela sua condição de humano errante. Ele não se abate com os erros, sabe que fazem parte da autoconstrução. Por isso, faz desses erros percebidos um motivo para errar no outro sentido do verbo: abre-se para vagar, para se deslocar, para viajar para dentro e para fora de si, mexendo-se, recriando-se.

Para Kohan, nessas circunstâncias, o erro (como errância) se mostra um princípio pedagógico em Freire, pois o principal inimigo político é o fatalismo, a convicção de que "as coisas não podem ser de outra maneira". Visto por esse ângulo, o entendimento da errância abre o porvir, a possibilidade de fazer diferente e melhor. Abre a ideia de que, como humanos, somos um projeto da mesma forma como temos projetos para o mundo. E da mesma forma que os projetos do mundo, o nosso projeto é construído de acertos e erros.

Sendo assim, a educação precisa estar ancorada na compreensão crítica e dialógica de que os seres humanos são um projeto em constante transformação, por isso, só tem sentido se de fato se crê que o futuro está aberto. Quem não entende que é humano, erra, e educa seres errantes, é melhor que se dedique a outra coisa que não a de educar. 
Isso significa que a educação só faz sentido quando o sonho político nasce durante ou depois da prática educativa, sendo uma política educacional que confronta o status quo, visto que este impede a errância e a evolução. Claro que o educador dialógico não tem direito de impor aos outros sua posição. O educador libertador, no entanto, precisa entregar-se à errância do perguntar, vivendo a pergunta e a investigação que ela pode iniciar, colocando que o mundo pode ser de muitas outras maneiras.

O quinto princípio é a infância. Infância não como um aspecto a ser educado, mas como algo que educa. Assim, a infância em Freire não é algo a se formar, mas algo para o qual devemos estar atentos: escutá-la, cuidá-la, mantê-la viva, vivê-la. Embora a prática educativa para Freire seja qualquer prática, com qualquer idade, em qualquer contexto, uma educação política é uma educação na infância, considerando: sensibilidade, curiosidade, inquietude, presença - características que extrapolam a educação tradicional, que vê na infância uma etapa cronológica para instaurar verdades prontas.

Para Kohan, uma forma de compreender essa concepção de infância em Freire é compreendendo a necessidade de ele indagar a própria infância. Retornar à infância cronológica é importante para se entender melhor suas marcas contrastantes. Uma das marcas das obras de Freire é que ele vai se infantilizando - no que se refere à preservação das potências da infância -, cultivando uma intimidade potente com uma infância não cronológica. O linguajar infantil aparece assim como uma força expressiva, uma forma conjuntiva e conectiva de viver a infância cronológica. Talvez mais do que isso: uma condição para que o ser humano continue a viver, transformando o que parece dado como definitivo.

"Menino conjunção" e "menino conectivo" são dois conceitos que significam uma força generativa, que coloca junto e faz somar sua história intelectual com sua história de infância. Enfatiza como foi alfabetizado na infância para refletir sobre as duas temporalidades que caminham lado a lado na educação: Chrónos e Kairós.

As ciências da vida estabelecem um Kairós para a escolarização e, dentro dela, a alfabetização. No entanto, a dureza das condições de vida permite que apenas uma minoria tenha esse tempo Kairós respeitado. E é justamente esse problema que Freire quer atacar. São os escolares não cronologicamente infantis que Paulo Freire está especialmente interessado em alfabetizar, pois, para um educador popular, o Kairós deve ser sempre o agora, porque é uma oportunidade.

Seguindo essa segunda forma de se relacionar com a infância, a educação poderia se ocupar de cultivá-la e atendê-la para que ela continue sempre viva, sendo 
o que é, em todas as idades. Com isso, a educação mais revolucionária é também uma educação menina, alegre, curiosa, perguntadora, ou seja, uma educação que respeite uma condição de vida educacional sensível ao autoquestionamento, ao engajamento em um ato pedagógico, ao mesmo tempo, inquieto e criativo, enfim, uma educação que veja, como Freire, a infância como uma força reinventora de mundo.

Por isso, a educação precisa ser uma educação menina, pois há muita infância no mundo, esperando ser ativada e revivida por meninas e meninos conjunções e meninos e meninas conectivos de todas as idades.

Como epílogo, Kohan se questiona: Freire pode ainda ajudar a pensar o que nos interessa pensar hoje, a viver a vida educacional e filosófica que nos interessa viver no presente? Sua resposta é sim. O sentido da educação freiriana é propiciar uma vida educadora mais inquieta e autoquestionadora sobre os sentidos de educar. Por isso, ela é inspiradora, não definidora de realidades. Viver Freire hoje é se reinventar e reinventar aquilo que Freire deixou de legado. Ele mesmo, Freire, queria isso. $\mathrm{E}$ isso põe por terra tudo aquilo que usam para acusar que o pensamento de Freire esvazia a ação dos educadores. Em verdade, o pensamento de Freire questiona, inspira e potencializa. Nunca pensado como fim. Sempre como meio.

\section{Referência}

KOHAN, Walter. Paulo Freire mais do que nunca: uma biografia filosófica. Belo Horizonte: Vestígio, 2019. 